\title{
CONTENT VARIATIONS OF CARBAMAZEPINE TABLETS IN IRAQI COMMUNITY PHARMACIES: APPLICATION OF HIGH-PERFORMANCE LIQUID CHROMATOGRAPHY ASSAY METHOD
}

\author{
MOHANAD NAJI SAHIB \\ Department of Faculty of Pharmacy, Al-Rafidain University College, Baghdad, Iraq. Email: mohanad_pharm@yahoo.com
}

Received: 22 September 2017, Revised and Accepted: 30 October 2018

\begin{abstract}
Objective: There is paucity in the literature and documentation regarding the post-marketing product quality in Iraq and Middle East countries in general. Therefore, a simple reverse phase high-performance liquid chromatography (RP-HPLC) method was developed and validated for the determination of carbamazepine (CMZ) content in post-marketed tablet dosage form.
\end{abstract}

Methods: The RP-HPLC analysis was run at a flow rate of $1 \mathrm{ml} / \mathrm{min}$ with a mixture of methanol: water (70:30) mobile phase using a Thermo Synchronise C18 column at a UV detection wavelength of $230 \mathrm{~nm}$. The method was validated for selectivity, linearity, precision, accuracy, limit of detection (LOD), limit of quantification (LOQ), solution stability, and robustness.

Results: The calibration curve was linear over a concentration range of $1-20 \mu \mathrm{g} / \mathrm{ml}\left(\mathrm{r}^{2}=0.9999\right)$ with LOD and LOQ of 0.01 and $0.04 \mu \mathrm{g} / \mathrm{ml}$, respectively. The intraday and interday precision and accuracy were between $0.04-1.67 \%$ and $0.04-0.78 \%$, respectively. The results of analysis of the four brands of CMZ tablets were passed the European Pharmacopoeia specification but with a high standard deviation of mean drug content of some brands.

Conclusion: This study shows that the quality of post-marketed drugs and/or the storage conditions in developing countries must be carefully assessed for a better therapeutic response.

Keywords: Carbamazepine, Drug content, High-performance liquid chromatography, Tablet quality.

(C) 2018 The Authors. Published by Innovare Academic Sciences Pvt Ltd. This is an open access article under the CC BY license (http://creativecommons. org/licenses/by/4. 0/) DOI: http://dx.doi.org/10.22159/ajpcr.2018.v11i2.22739

\section{INTRODUCTION}

Substandard drug is a genuine product but has incorrect amount of active pharmaceutical ingredient [1-3]. This may be due to poor manufacturing quality or excessive decomposition of active ingredient [4], while counterfeit drugs have defined by the World Health Organization as those that are "deliberately and fraudulently mislabeled with respect to identity and/or source" [5]. Poor regulation of pharmaceutical companies, coordinated criminal organization, and system corruption was linked with the counterfeit drug trading [6].

In Iraq, although the rigorous order for licensing of import and/or manufacture of drugs, the complex transactions involving many intermediaries, lack of regulation in many border sites and high demand make the market for substandard drugs more lucrative one. This study is the first one in this field in Iraq and Middle East countries. It is a pilot study to assess carbamazepine (CMZ) tablet content in Iraqi markets. CMZ is an antiepileptic drug (AED), and substandard formulations of CMZ will have serious effects. The main ones are being treatment failures, prolonged illnesses, and unexpected side effects. Therefore, the aims of this study are to develop a simple and sensitive reverse phase-high performance liquid chromatography (RP-HPLC) method to analyze CMZ and to use the developed method in the quality control analysis.

\section{METHODS}

\section{Purchasing samples}

Four marketed brands of CMZ tablets were commonly available in the community pharmacies. 10 strips for each brand were purchased (1 strip from each pharmacy) and named as Batch 1, 2, 3, and 4 (B1, B2, $\mathrm{B} 3$, and B4). The samples were collected by local collaborators who had no idea about the purpose of the purchases.
Materials and chromatographic conditions

The HPLC system used in this study was Shimadzu with a UV/Vis detector (SPD-20A; Shimadzu, Japan). The analyte separation was accomplished at $40^{\circ} \mathrm{C}$ (CTO-10AS VP, Shimadzu column oven) using a Synchronise C18 analytical column, $150 \times 4.6 \mathrm{~mm}$ ID, $5 \mu \mathrm{M}$ (Thermo, USA) with a mobile phase mixture of methanol:water (70:30). The mobile phase was filtered under vacuum through a $0.45 \mu$ m nylon filter (Whatman, UK) and degassed before use. A flow rate and wavelength were set at $1.0 \mathrm{ml} / \mathrm{min}$ and $230 \mathrm{~nm}$, respectively. The injection volume was $20 \mu \mathrm{L}$. CMZ was obtained from Tokyo Chemical Industry Co., LTD (Tokyo, Japan) and methanol HPLC grade was obtained from J. T. Baker Analyzed (Shanghai, China).

\section{Solutions for the validation study}

A stock solution of $1 \mathrm{mg} / \mathrm{ml}$ of CMZ in methanol was prepared. The working solutions containing 1 to $20 \mu \mathrm{g} / \mathrm{ml}$ of CMZ were prepared, and $20 \mu \mathrm{L}$ aliquots were injected 6 times and eluted under the reported chromatographic conditions. For regression equation calculation, the average peak area versus the concentration of CMZ in $\mu \mathrm{g} / \mathrm{ml}$ was plotted.

\section{Preparation of the sample solution}

CMZ tablet was crushed to a homogeneous powder then dissolved in $50 \mathrm{ml}$ of methanol in $100 \mathrm{ml}$ volumetric flask with the help of sonicator. Thereafter, the volume was made up to mark with methanol and filtered through a $0.45 \mu \mathrm{m}$ nylon membrane filter (Whatman, UK) under vacuum. The filtrate was further diluted to obtain sample solutions of concentrations within the calibration curve range.

\section{METHOD VALIDATION}

\section{Selectivity}

The selectivity of the developed method was determined by checking the interference between the spectral purity obtained from working 
standard solution and sample solution containing excipients that present in the pharmaceutical products.

\section{Linearity}

The linearity of the method was evaluated using six calibration curves in the concentration range of $1-20 \mu \mathrm{g} / \mathrm{ml}$. The linear regression analysis method was used to construct the calibration curves plot (peak area of the analyte against the corresponding concentration).

\section{Precision}

Repeatability and reproducibility were evaluated for method precision. Quality control samples of 1, 5, and $20 \mu \mathrm{g} / \mathrm{ml}$ (low, medium, and high concentrations, respectively) were analyzing to evaluate intra- and inter-day precision. Six replicates of three concentration levels on the same day and 3 different days were analyzed for intra- and inter-day precision, respectively.

\section{Accuracy}

A standard addition method was used to assess the accuracy of the method. The addition method was performed by adding a known amount of standard drug to $80 \%, 100 \%$, and $120 \%$ of the target test concentrations of the pre-analyzed tablet formulation. Three determinations were performed for each level.

\section{Limit of detection (LOD) and limit of quantification (LOQ)}

The standard deviation and slope of the response were used to determine the sensitivity of the method as described in ICH guidelines Q2 (R1) [7]. The LOD and LOQ were calculated according to the following equations:

$\mathrm{LOD}=3.3 \sigma / \mathrm{S} ; \mathrm{LOQ}=10 \sigma / \mathrm{S}$

Where $\sigma=$ the standard deviation of the response; $\mathrm{S}=$ the slope of the calibration curve.

\section{Solution stability}

Reference solutions with low, medium, and high-quality control samples were stored in the refrigerator for 14 days. Then, the samples were re-analyzed by employing freshly prepared standard solutions.

\section{Method robustness}

The method robustness was assessed as a function of altering methanol and water mobile phase ratio over a range of $\pm 5 \%$. The concentration of solution analyzed was $20 \mu \mathrm{g} / \mathrm{ml}(\mathrm{n}=6)$

\section{RESULTS AND DISCUSSION}

\section{Method optimization}

The mobile phase (methanol: water) was chosen due to its availability, low cost, and gave good peak resolution. In addition, using water can increase the lifespan of the column if compared to buffer salt [8].

\section{Method validation}

As described in ICH guideline Q2 (R1) any newly developed method must be validated before its use for the intended [7]. For this purpose, this method was validated for its selectivity, linearity, precision, accuracy, LOD, LOQ solution stability, and robustness.

\section{Selectivity}

The chromatographic condition revealed to be selective for CMZ. Fig. $1 \mathrm{a}$ and $\mathrm{b}$ show a typical separation of CMZ $(20 \mu \mathrm{g} / \mathrm{ml})$ with no interfering peaks from mobile phase, respectively. Moreover, there were insignificant interfering peaks from sample solution (containing excipients) with CMZ at a retention time of 2.5 min (Fig. 1c) which indicate the selectivity of the developed method. Therefore, the results showed that the newly developed method was appropriate for quality control analysis.

\section{Linearity}

The linear regression equation with a correlation coefficient of 0.9999 was $y=100635( \pm 359) \times+63270( \pm 1006)$. This result revealed an excellent correlation between the peak area and concentration of the analyte. The linearity results are presented in Table 1.

\section{Precision}

The relative standard deviation percent (\% RSD) for intraday and interday precision was ranged from 0.04 to 1.67 . The RSD\% of the peak area of six replicates was found to be $<2 \%$ and within the acceptable limits [9]. The results of precision are shown in Table 2.

\section{Accuracy}

The results of the recovery study are shown in Table 3 . All the results were within the acceptable limits which indicate the accuracy of the validated method to detect CMZ in tablet formulation [9]

\section{$\angle O D$ and $L O Q$}

The LOD and LOQ were found to be $0.01 \mu \mathrm{g} / \mathrm{ml}$ and $0.04 \mu \mathrm{g} / \mathrm{ml}$, respectively. The results of LOD and LOQ were indicating a high sensitivity of the method.

\section{Solution stability}

The results of the stability test are shown in Table 2 . The results revealed that the drug was stable in the above-mentioned condition which was sufficient to complete the whole analytical process.

Table 1: Summary of calibration curve results for CMZ, $n=6$

\begin{tabular}{lll}
\hline $\begin{array}{l}\text { Theoretical CMZ } \\
\text { concentration } \boldsymbol{\mu g} / \mathbf{m l})\end{array}$ & RSD (\%)* & RE (\%) ** \\
\hline 20 & 0.05 & 0.06 \\
10 & 0.06 & 0.4 \\
5 & 0.1 & 0.9 \\
2 & 0.8 & 1.2 \\
1 & 1.4 & 1.89 \\
\hline
\end{tabular}

${ }^{*} \mathrm{RSD} \%$, relative standard deviation percent, ${ }^{* *} \mathrm{RE} \%$, relative error percent, CMZ: Carbamazepine

Table 2: Experimental values of mean concentration of CMZ, RSD (\%) presented for validation parameters of CMZ

\begin{tabular}{lll}
\hline Parameters & $\begin{array}{l}\text { Theoretical } \mathbf{C M Z} \\
\text { concentration } \boldsymbol{\mu g} / \mathbf{m l})\end{array}$ & \% RSD \\
\hline Intraday & 20 & 0.04 \\
& 5 & 0.2 \\
Interday & 1 & 1.5 \\
& 20 & 0.09 \\
Short-term stability & 5 & 1.1 \\
& 1 & 1.67 \\
& 50.50 \\
& 1 & 1.50 \\
& 5 & 1.04 \\
\hline
\end{tabular}

CMZ: Carbamazepine, RSD: Relative standard deviation

Table 3: Recovery data for CMZ of four different batches

\begin{tabular}{lll}
\hline $\begin{array}{l}\text { \% of target } \\
\text { concentration }\end{array}$ & Mean \% recovery & RSD \% \\
\hline 80 & 96.44 & 0.78 \\
100 & 101.11 & 0.04 \\
120 & 98.76 & 0.10 \\
\hline
\end{tabular}

$100 \%$ of the target concentration is equivalent to $10 \mu \mathrm{g} / \mathrm{ml}$ of three replicates. CMZ: carbamazepine, RSD: Relative standard deviation 


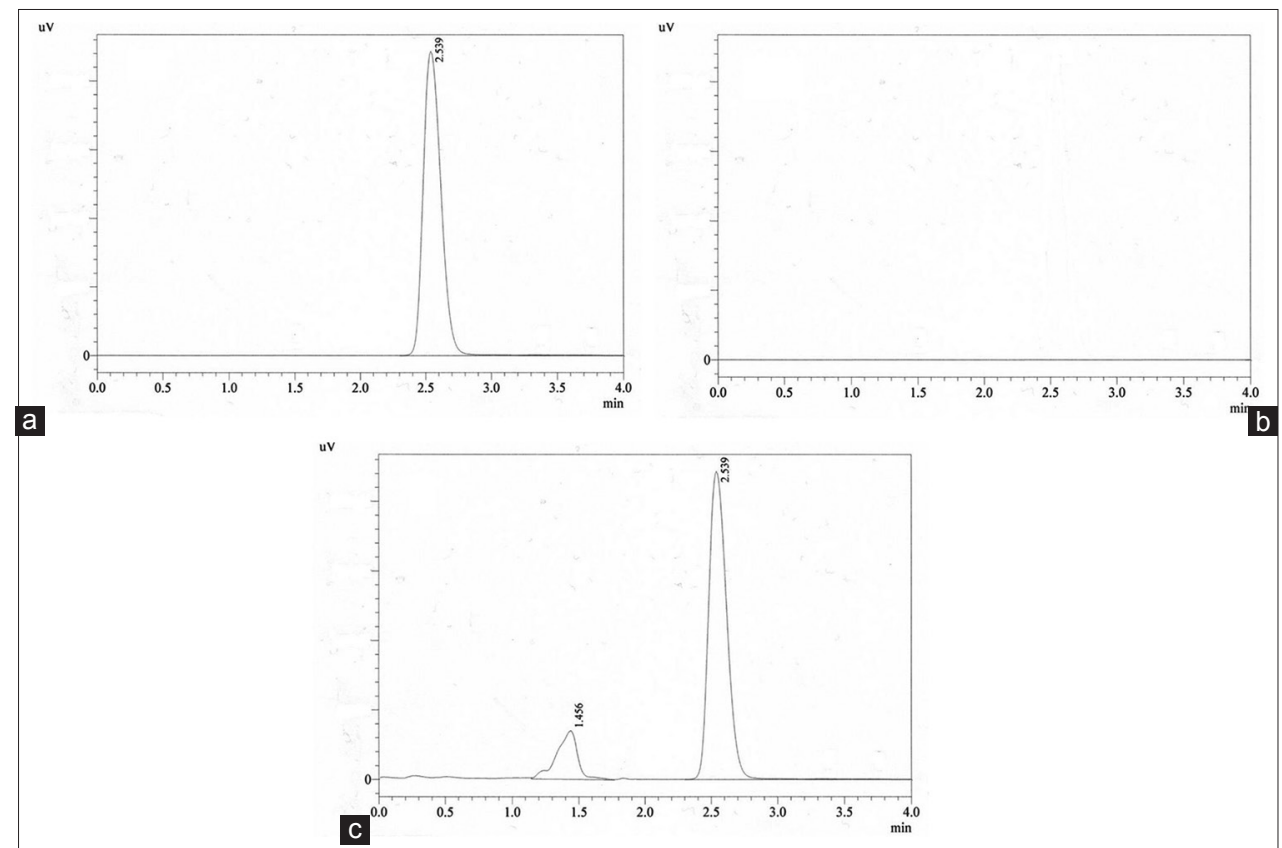

Fig. 1: Characteristic high-performance liquid chromatography-ultraviolet chromatograms of carbamazepine (CMZ). (a) Spiked placebo, (b) mobile phase, and (c) sample solution; the retention time of CMZ is $2.5 \mathrm{~min}$

\section{Robustness}

There were unpredictable changes in the chromatograms demonstrated with $\%$ RSD range (0.6-1.1\%). The low values of the \%RSD indicated the robustness of the method.

\section{Method application}

Four marketed CMZ tablets were analyzed for drug content (B1, B2, B3, and B4). According to European Pharmacopoeia [10], the criteria for drug content states that CMZ tablets must contain not $<85 \%$ and not more than $115 \%$ of CMZ stated on the label. The results of analysis of the four brands of CMZ tablets are represented in Table 4.

From the results, all batches passed the EP specification. However, the results showed higher standard deviation for Carbasam ${ }^{\circledR}$ and Tegral ${ }^{\circledR}$ compared to Tegretol ${ }^{\circledR}$ and Taver $^{\circledR}$ tablets. This is due high variation in drug content in B2 and B3 samples (data not shown). Many reasons could affect this result. Inadequate production process validation and quality control during the manufacturing process may be the main reason.

This result is consistent with the previous report of the quality of antimalarial drugs [11]. In addition, Carbasam ${ }^{\circledR}$ tablets were stored in a box containing more than 100 strips and soled to pharmacies as individual strips which result in them to be more exposed to heat, light, and humidity. Moreover, the type of the packing strip is another factor needed to be address $[12,13]$. In addition to the above, in Iraq, power outage (more than $15 \mathrm{~h}$ in hot summer) is also play a role in these results. However, further studies were needed to assess these factors.

Finally, this study shows that the quality of post-marketed drugs and/ or the storage conditions in developing countries must be carefully assessed for a better therapeutic response. In addition, the AED quality is important because seizure is a chronic disease and concerns a lot of individuals in developing countries. Moreover, development of a simple method for detection any therapeutic agent is important for industrial application so can improve production processes $[14,15]$.

\section{CONCLUSION}

A simple and sensitive RP-HPLC method was developed for the determination of $\mathrm{CMZ}$ in tablet dosage forms. All validation parameters tested results were satisfactory. The method is cost-effective due to
Table 4: Assay results of carbamazepine tablets

\begin{tabular}{lll}
\hline Batch & Brand name & Average content $(\%), \mathbf{n = 1 0 0}$ \\
\hline B1 & Tegretol $^{\circledR}$ & $96.33 \pm 2.66$ \\
B2 & Carbasam $^{\circledR}$ & $95.43 \pm 9.32$ \\
B3 & Tegral $^{\circledR}$ & $93.86 \pm 6.11$ \\
B4 & Taver $^{\circledR}$ & $95.33 \pm 3.63$ \\
\hline
\end{tabular}

short retention time which allowed a large number of samples to be analyzed within a short period of time. The developed method was successfully applied for drug content analysis of commercially available CMZ tablets. All batches passed the drug content criteria but with a high variation which may cause inadequate control of seizures and tolerance developments to AED which may be attributed to the quality aspect of the drug.

\section{DECLARATION}

The author confirms that the manuscript has not been submitted to any other Journal for publication

\section{CONFLICTS OF INTERESTS}

The author has none to declare.

\section{AUTHOR'S CONTRIBUTIONS}

Sahib MN is responsible for study design, data acquisition, and manuscript preparation.

\section{REFERENCES}

1. Videau J, Fundafunda B. Generic Drugs: The Hidden issues of Quality and Cost. WHO Drug Inf 2000;14:77-81.

2. WHO. Quality Assurance of Pharmaceuticals - A Compendium of Guidelines and Related Materials. Report. Geneva: World Health Organization; 1997.

3. WHO. Quality Assurance of Pharmaceuticals - A Compendium of Guidelines and Related Materials. Report. Geneva: World Health Organization; 2007.

4. Kelesidis T, Kelesidis I, Rafailidis PI, Falagas ME. Counterfeit or substandard antimicrobial drugs: A review of the scientific evidence. J Antimicrob Chemother 2007;60:214-36. 
5. WHO. Counterfeit Drugs. Guidelines for the Development of Measures to Combat Counterfeit Drugs. Report. Geneva: World Health Organization; 1999.

6. Moken MC. Fake pharmaceuticals: How they and relevant legislation or lack thereof contribute to consistently high and increasing drug prices. Am J Law Med 2003;29:525-42.

7. ICH. Validation of Analytical Procedures: Text and Methodology Q2 (R1). Report. Contract No.: 4/2. Geneva, Switzerland: ICH; 2005.

8. Neue U, Alden B, Iraneta P, Alberto M, Grumbach E, Tran K, et al. HPLC columns for pharmaceutical analysis. In: Ahuja S, Dong M, editors. Handbook of Pharmaceutical Analysis by HPLC. London: Elsevier Academic Press; 2005. p. 98-102.

9. Épshtein NA. Validation of HPLC techniques for pharmaceutical analysis. Pharm Chem J 2004;38:212-28.

10. European Pharmacopoeia. Uniformity of Content of Single-Dose Preparations; 2005.
11. Petralanda I. Quality of antimalarial drugs and resistance to plasmodium vivax in amazonian region. Lancet 1995;345:1433.

12. al-Zein H, Riad LE, Abd-Elbary A. Effect of packaging and storage on the stability of carbamazepine tablets. Drug Dev Ind Pharm 1999;25:223-7.

13. Yang D, Plianbangchang P, Visavarungroj N, Rujivipat S. Quality of pharmaceutical items available from drugstores in phnom penh, cambodia. Southeast Asian J Trop Med Public Health 2004;35:741-7.

14. Vinay R, Devi VK. Development and validation of a highly sensitive high-performance liquid chromatography (HPLC) method for the estimation of methotrexate (MTX) pure drug and marketed formulation in spiked rat plasma. Int J Pharm Pharm Sci 2016;8:313-7.

15. Rajoriya V, Soni A, Kashaw V. Method development and validation of fast dissolving tablet of ramipril by HPLC method. Int J Pharm Pharm Sci 2016;8:174-8. 